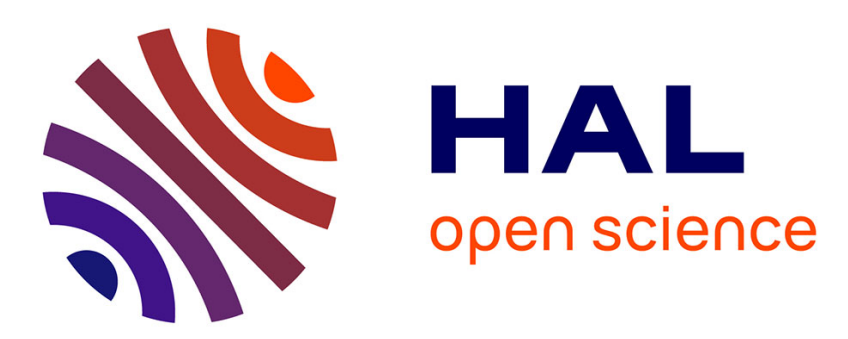

\title{
Interaction of AC Grid Filters in Aircraft and Influence of the System Dynamic Behaviour
}

Blazej Czerniewski, Andrea Formentini, David Dewar, Pericle Zanchetta, J-L. Schanen

\section{- To cite this version:}

Blazej Czerniewski, Andrea Formentini, David Dewar, Pericle Zanchetta, J-L. Schanen. Interaction of AC Grid Filters in Aircraft and Influence of the System Dynamic Behaviour. IEEE Transactions on Industry Applications, 2022, IEEE transactions on IAS, vol. 58 (2), pp.2134-2143. 10.1109/TIA.2021.3133212 . hal-03584518

\section{HAL Id: hal-03584518 https://hal.science/hal-03584518}

Submitted on 22 Feb 2022

HAL is a multi-disciplinary open access archive for the deposit and dissemination of scientific research documents, whether they are published or not. The documents may come from teaching and research institutions in France or abroad, or from public or private research centers.
L'archive ouverte pluridisciplinaire HAL, est destinée au dépôt et à la diffusion de documents scientifiques de niveau recherche, publiés ou non, émanant des établissements d'enseignement et de recherche français ou étrangers, des laboratoires publics ou privés. 


\title{
Interaction of AC Grid Filters in Aircraft and Influence of the System Dynamic Behaviour
}

\author{
Blazej Czerniewski, Andrea Formentini, Member, IEEE, David Dewar, Student Member, IEEE, \\ Pericle Zanchetta, Fellow, IEEE, and Jean-Luc Schanen, Senior Member, IEEE
}

\begin{abstract}
This paper deals with the impact of harmonic filters interactions in the aircraft grid, in particular, their influence on the control performance of each subsystem. The study has been carried out on a notional electrical system composed of two three-phase power converters - a Voltage Source Inverter (VSI) and an Active Front End (AFE). The beginning of the paper presents the origin of the issue - trend of reducing the filter size and weight, which is especially true in aircraft industry. Then, the roles of the filter and their design challenges are discussed. The next part of the paper describes the controller's constraints, its design and the control system modelling approach including a specially developed simulation tool used for the interactions analysis. Simulation results with the experimental verification are presented showing the interactions impact on the system dynamics. Finally, optimization of the filters under dynamic control constraints considering system's components interaction are presented as the simulation tool application.
\end{abstract}

Index Terms-Active front-end, AFE, aerospace, converter control, design, harmonic filters, power quality, optimization, SQP, voltage source inverter, VSI

\section{INTRODUCTION}

D YNAMIC technology development results in a drastic growth of emission which causes many environmental issues. Aeronautics is one of the most pollutant industrial fields. The proposed solution to reduce pollution is aircraft electrification due to its potential in decrease of the plane's mass and therefore reduction of exploitation cost and environmental impact [1]. Decreasing weight in aircraft can result in saving tons of fuel and reduction of $\mathrm{CO} 2$ emission per year for all air traffic [2]. Moreover, the increased amount of electric devices in the aircraft can lead to an improvement of the distribution system reliability and efficiency [3].
The More Electric Aircraft (MEA) is a major concept in electrification of the aircraft. The goal is to replace conventional devices, which are usually powered by pneumatic, hydraulic or mechanical power sources, with electrical systems [4]. Consequently, the aircraft distribution network becomes increasingly complex. That kind of electric grid includes numerous power electronics converters which makes it even more complex. Despite many advantages of MEA, such complexity can lead to some issues due to the interactions in the grid. This can affect system components' operation (power quality, control, dynamic behaviour...) and causes issues related to aircraft standards compliance [5]. The common approach in power electronics converters is to attenuate harmonics generated by converter's switching with filters. They have to be designed in order to meet total harmonic distortion (THD) requirements in the grid. The filters have a direct influence on the dynamic behaviour of the system. Due to the interactions of the filters inside the grid, the dynamic response is modified. Therefore, it is necessary to recognize and consider or eliminate these interactions in order to be able to design a system which meets both THD and dynamic requirements.

In order to better understand the interactions in the aircraft electrical grid, a simple case has been studied. The electrical network is composed of two power electronic converters commonly used in aircraft applications - Active Front End (AFE) and Voltage Source Inverter (VSI). Both converters are controlled by PI controllers in a closed-loop system. The grid schematic is presented in the Fig. 1. The AC grid shares three filter elements: the L-C output filter of the VSI $\left(\mathrm{L}_{V S I}, \mathrm{C}_{V S I}\right)$ and the input inductor of the $\operatorname{AFE}\left(\mathrm{L}_{A F E}\right)$. This paper will focus on this filter only, and show that trying to minimize it too

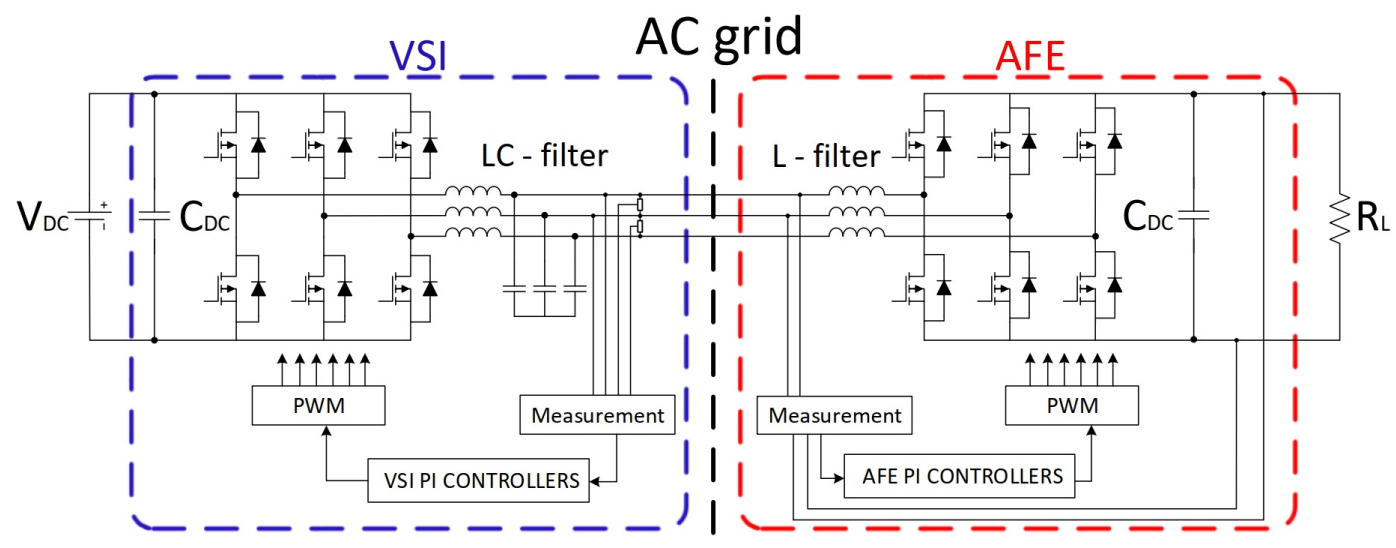

Fig. 1: The study case electrical grid. 
much may fail in meeting the dynamic constraints. A method for a global design of the filter including both THD and dynamic constraints will be proposed and illustrated. It is not the objective of the paper to design the full system, therefore both converters (DC capacitance, switching frequencies) will be fixed.

\section{Filters IN POWER ElECTRONICS GRID}

The main role of the harmonic filter in a converter is to decrease the interference signal at switching frequency and its harmonic frequencies. Another is to suppress the noise and surge from outside of the converter [6]. Power electronics harmonic filters are designed according to power quality standards in order to comply with the required THD limitation.

\section{A. Design challenges of the Filters}

Technology development resulted in a significant increase of the amount of power electronics devices [7]. Thus, high expectations are placed for a modern converter design, especially in the aircraft industry. Converters size and weight tends to be minimized while keeping as high efficiency and standards compliance as possible.

The filters, as an integral part of a converter, play a major role in its size and weight [8]. Therefore, the common design practice, while optimizing converter's size and weight, is to reduce them as much as possible, especially the inductors due to their bulkiness. This can be done by increasing switching frequency of the converter, for instance. However, it increases the converter's losses and might generate additional EMI issues.

Minimizing the filters can result in some issues related to the dynamic behaviour of the converter or even in the whole grid [5]. Changing the filter values may cause a dynamic performance decrease and consequently not complying with the standards. Furthermore, in some cases it might lead to some issues with the stability of the system. The problem can be even more complex, since the origin might be not only caused by the filters of the single converter but also by an interaction between several devices in the grid.

\section{B. Filters in aircraft grid study case}

The AC grid analysed in the paper is composed of the output filter of the VSI and the input filter of the AFE. The other DC filters (input capacitance of VSI, output capacitance of AFE) are not considered in the study. The nominal parameters of both VSI and AFE converters considered in the paper are given in the Tab. I below.

TABLE I: VSI and AFE converters nominal parameters.

\begin{tabular}{cc}
\hline VSI & AFE \\
\hline $\mathrm{P}_{N}=1.5 \mathrm{~kW}$ & $\mathrm{P}_{N}=1.5 \mathrm{~kW}$ \\
$\mathrm{~V}_{\text {in }}=350 \mathrm{~V} \mathrm{dc}$ & $\mathrm{V}_{\text {in }}=115 \mathrm{~V} \mathrm{AC} \mathrm{rms}$ \\
$\mathrm{V}_{\text {out }}=115[\mathrm{~V}] \mathrm{AC} \mathrm{rms}$ & $\mathrm{V}_{\text {out }}=350 \mathrm{~V} \mathrm{dc}$ \\
$\mathrm{f}_{\text {sw }}=20 \mathrm{kHz}$ & $\mathrm{f}_{\text {sw }}=20 \mathrm{kHz}$ \\
$\mathrm{f}_{n}=400 \mathrm{~Hz}$ & - \\
\hline
\end{tabular}

The main role of the VSI output filter is to attenuate voltage ripples originated from the inverter switching [9]-[11]. The aim is to design a filter which meets the harmonic standards requirement - the converter's output voltage THD smaller than $5 \%-10 \%$ (5\% for MIL704F and 8-10\% for DO160F). The inductance of the VSI output filter has been chosen based on its maximum peak-to-peak current. As a rule of thumb, this current ripple has been fixed to $40 \%\left(\Delta I_{L_{V S I}}=7.38 \mathrm{~A}\right)$, to limit inductor losses. The filter cut-off frequency [12] is then tuned to attenuate converter's switching harmonics. The computed values are $L_{V S I}=296.5 \mu \mathrm{H}$ and $C_{V S I}=31.8 \mu \mathrm{F}$. The inductance for given current ripple and filter cut-off frequency $f_{c}$ are calculated below.

$$
\begin{gathered}
L_{V S I}=\frac{1}{8} \frac{V_{i n}}{\Delta I_{L_{V S I}} f_{s w}}=296.5 \mu H \\
f_{c}=\frac{1}{2 \pi \sqrt{L_{V S I} C_{V S I}}}=1.63 \mathrm{kHz}
\end{gathered}
$$

$V_{i n}$ is converter input voltage, $\Delta I_{L_{V S I}}$ is inductor maximum current ripple, $f_{s w}$ is converter's switching frequency.

The AFE input filter is a series inductor which is a basic topology for this application. Its goal is to prevent AFE switching harmonics from being injected in the AC grid. The filter is designed to reduce the input current ripple (usually it should be $20 \%-40 \%$ ) and therefore minimize the harmonic content in the AC grid [13]. The filter inductor value $\left(L_{A F E}\right)$ is computed based on the maximum current ripple following again the engineering rule of thumb, this time being $20 \%$ $\left(\Delta I_{L_{A F E}}=3.68 \mathrm{~A}\right)$ for an AFE [14]. The inductor computation is presented below.

$$
L_{A F E}=\frac{V_{i n}}{\sqrt{6} f_{s w} \Delta I_{L_{A F E}}}=636.3 \mu H
$$

$V_{i n}$ is converter input voltage, $f_{s w}$ is converter switching frequency and $\Delta I_{L_{A F E}}$ is inductor maximum current ripple which is $20 \%$ of the input peak current.

\section{THE IMPACT OF THE INTERACTION ON THE CONTROL PERFORMANCE}

The focus of the paper is to study the influence of the harmonic filters on the dynamic behaviour of the system. The analysed case is a simple AC grid composed of two power electronics converters VSI and AFE. The VSI, supplied by a DC source, generates $115 \mathrm{~V}$ (RMS) $400 \mathrm{~Hz}$ AC voltage on the output which are standard parameters for a grid in aircraft. The AFE is supplied by the AC grid generated by the VSI. Both converters are controlled by PI controllers. The switching frequency of both converters is constant and set to $20 \mathrm{kHz}$ which is maximum switching frequency of the hardware setup described in section V. Of course, increasing the switching frequency would result in reduced filters, but this would also impact the power converters design which is out of the scope of this paper. The dynamic behaviour of the system is tested by the resistive step load response of each converter which is equal to nominal power of the system. 


\section{A. Control system constraints}

In order to analyse the influence of the harmonic filters on the system control performance behaviour, the step-load response is compared with the standard for different harmonic filter values. The requirements for aircraft devices and grid are described in the standards such as MIL704 (military) or RTCA DO-160 (civil).

The standard which has been chosen for consideration is MIL704 since it is more restrictive. The dynamic behaviour requirements for each converter in avionic grid is voltage overshoot or undershoot and settling time. The constraints depend on the type of the converter ( $\mathrm{dc}$ or ac) and its voltage rate. The visual description of the requirements used in the analysis for both VSI and AFE is presented in Fig. 2, red lines showing the limits. VSI output voltage is presented in d-frame of Park transform for better transient presentation.
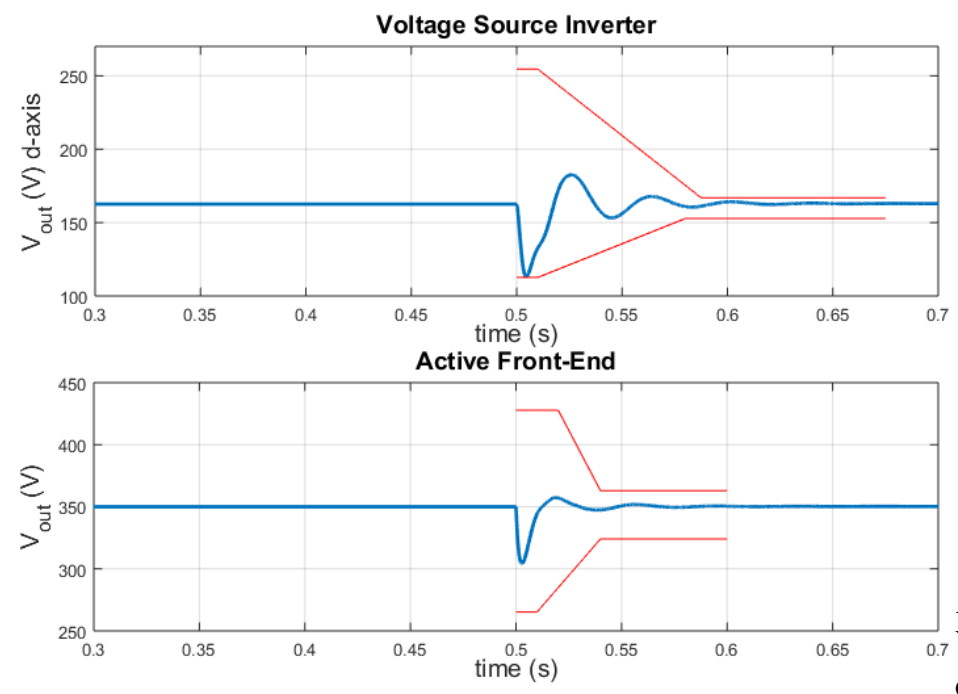

Fig. 2: Output voltages of VSI (d-axis) and AFE output voltages with MIL704 requirements (marked as red lines).

\section{B. Control design}

The control system has been designed separately for each converter. Each converter's control is realized with PI Controllers and has two loops which are based on dq-frames composition [15].

The VSI control is presented in Fig.3. The measured output voltage $\left(V_{a b}, V_{b c}\right)$ and current $\left(I_{a}, I_{b}\right)$ are transformed to the dq-frames which are inputs of two control loops. The loops control the VSI output voltage and current through PI controllers. This simple control strategy has been chosen due to its simplicity and robustness. Moreover this allows to underline some dynamic behaviour limitations which would not have appeared in advanced control strategies. The VSI output voltage reference in d-frame is set to converter nominal value $V_{c d}=115 \mathrm{~V} \mathrm{rms}$, whereas $V_{c q}$ is set to 0 in order to keep the unity power factor. The PI voltage and current control gains are computed based on the converter's topology. The control loops outputs are modulation indexes $\left(m_{d}\right.$ and $\left.m_{q}\right)$ which modify PWM signal of the converter's switches. The computation of the PI gains is presented below (Eq. 4).

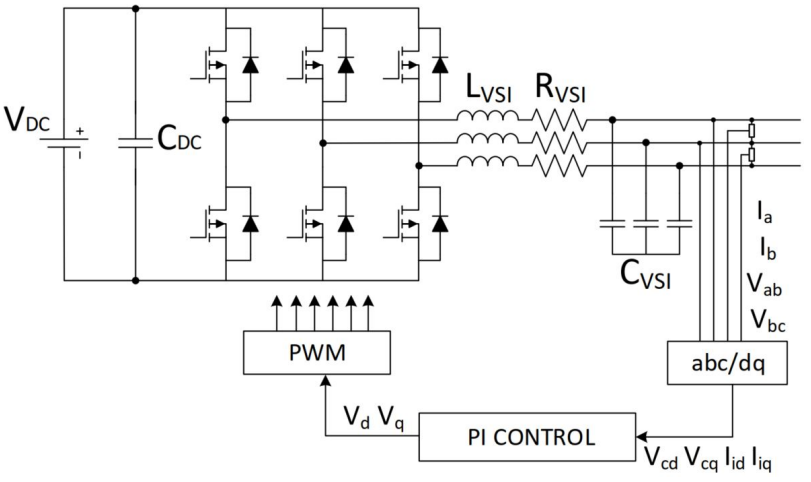

(a) VSI control system.

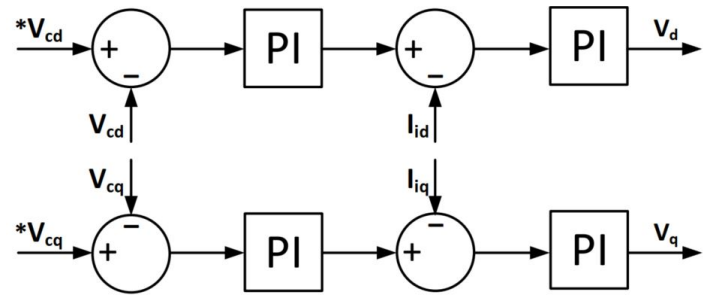

(b) VSI PI controller loops.

Fig. 3: VSI control system based on PI controllers.

$$
\begin{gathered}
K_{p v_{V S I}}=2 \zeta C_{V S I} f_{v_{V S I}} 2 \pi \\
K_{i v_{V S I}}=C_{V S I}\left(f_{v_{V S I}} 2 \pi\right)^{2} \\
K_{p i_{V S I}}=2 \zeta L_{V S I} f_{i_{V S I}} 2 \pi-R_{V S I} \\
K_{i i_{V S I}}=L_{V S I}\left(f_{i_{V S I}} 2 \pi\right)^{2}
\end{gathered}
$$

$K_{p v_{V S I}}$ and $K_{i v_{V S I}}$ are proportional and integral gains of the VSI voltage loop. $K_{p i_{V S I}}$ and $K_{i i_{V S I}}$ and integral gains of the current loop accordingly. $L_{V S I}$ is VSI LC filter inductance, $R_{V S I}$ inductor parasitic resistance and $C_{V S I}$ is LC filter capacitance. $f_{v_{V S I}}$ and $f_{i_{V S I}}$ are PI controller bandwidths of VSI current and voltage loops and they are set accordingly to comply with the standards (possibly fast controller with reasonable voltage undershoot). $\zeta$ is a damping factor and was arbitrary set to unity.

The AFE control is presented in Fig.4. The measured output voltage $\left(V_{d c a}\right)$ and input current $\left(I_{a}, I_{b}\right)$ are transformed to the dq-frames which are the inputs of two control loops. Similar to the VSI control, the loops control the AFE output voltage and input current through PI controllers. The AFE output voltage reference is set to converter nominal value $V_{d c a}=350 \mathrm{~V}$, whereas $I_{a q}$ is set to 0 in order to keep the unity power factor. The control loops outputs are modulation indexes $\left(p_{d}\right.$ and $\left.p_{q}\right)$ which modify PWM signal of the converter's switches. The PI voltage and current control gains are computed below (Eq. $5)$.

$$
\begin{gathered}
K_{p v_{A F E}}=2 \zeta C_{A F E} f_{v_{A F E}} 2 \pi \\
K_{i v_{A F E}}=C_{A F E}\left(f_{v_{A F E}} 2 \pi\right)^{2} \\
K_{p i_{A F E}}=-2 \zeta L_{A F E} f_{i_{A F E}} 2 \pi-R_{A F E} \\
K_{i i_{A F E}}=-L_{A F E}\left(f_{i_{A F E}} 2 \pi\right)^{2}
\end{gathered}
$$

$K_{p v_{A F E}}$ and $K_{i v_{A F E}}$ are proportional and integral gains of the 


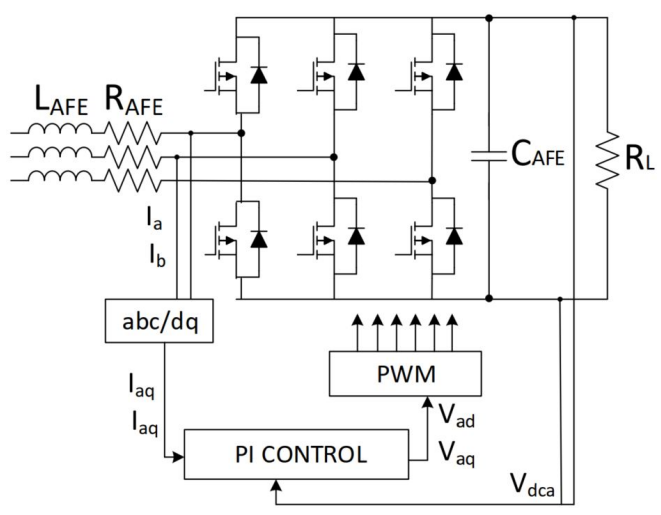

(a) AFE control system.

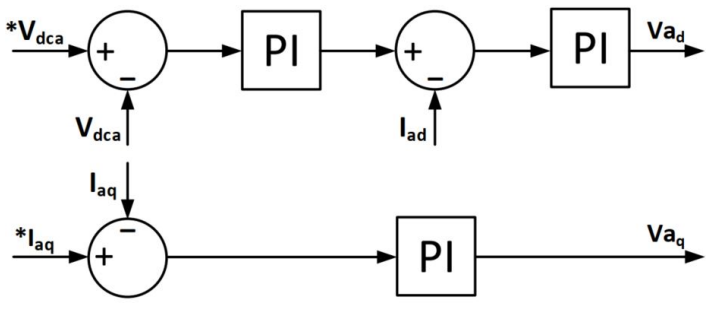

(b) AFE PI controller loops.

Fig. 4: AFE control system based on PI controllers.

AFE voltage loop. $K_{p i_{A F E}}$ and $K_{i i_{A F E}}$ are proportional and integral gains of the AFE current loop. $L_{A F E}$ is AFE input filter and $R_{A F E}$ its parasitic resistance, $C_{A F E}$ is an output DC filter capacitance of the AFE. $f_{v_{A F E}}$ and $f_{i_{A F E}}$ are the PI controller bandwidths and they are also set to meet the standards. $\zeta$ which is a damping factor similarly to VSI is set to unity.

\section{Control system simulation - switching model}

The preliminary analysis was conducted by using a switching model created in MATLAB Simulink environment. The model includes converters with filters, switching cells and control circuit. The control system used in the model is described in the paragraph III-B. The model was used to test the step-load response for both input and output harmonic filters values. To check the influence of the passive filters only, controllers' bandwidths were not changed. The simulation study revealed that the parameters of the grid that have the most impact on the dynamic behaviour of the system are LC filter of the VSI and L filter of the AFE. Reducing their values decreases the control performance. The analysis revealed that the interaction between harmonic filters and the dynamic behaviour occurs not only in each converter separately but also between them. Manipulation of the VSI LC filter affects the AFE output voltage step load response and changing AFE input filter values affects VSI output voltage response. The example results are presented in Fig.5 and Fig.6. Fig. 5 shows the step load response of the VSI and AFE output voltages for different values of the AFE input filter. The VSI output voltage is modified without changing any parameters of this converter. As presented, for small values of the AFE filter both VSI and AFE do not meet the standard requirements. Similar relation occurs with manipulation of the LC filter. It was not possible to find any solution meeting the dynamic requirements for very small values of the LC filter capacitor, even by manipulating the PI controllers bandwidth.

\section{Control SyStem Simulation TOOL}

The analysis revealed that the interactions occur between several elements of the grid, in addition the dynamic response is also dependent on the bandwidths of the controllers. Simulation of every possible case to study all interactions is not viable. Moreover, the switching model used for simulation demands a lot of computational power which increases the time effort needed for analysis. Furthermore, describing the control system as a mathematical expression would be a very complex and time consuming task. Therefore, a dedicated simulation tool was developed for further study purposes.
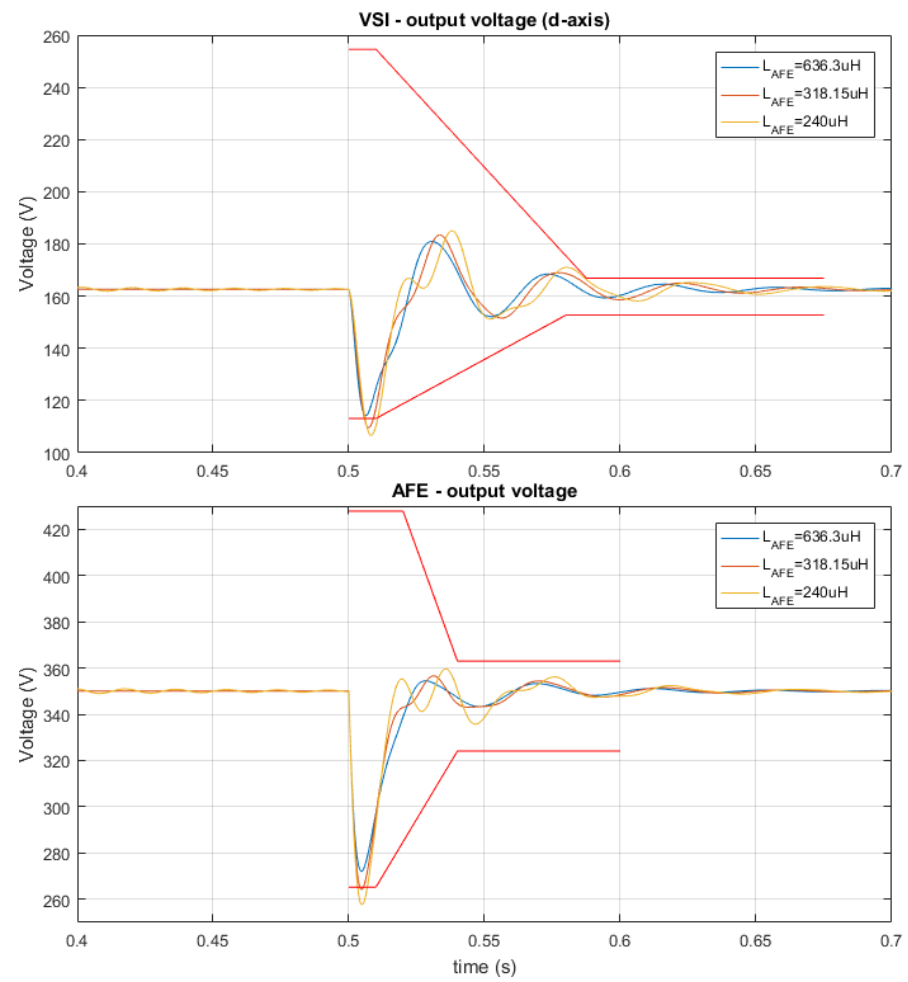

Fig. 5: Comparison of VSI and AFE output voltage response for a nominal power step load $(1.5 \mathrm{~kW})$ for different AFE input inductor values. All other parameters are unchanged. 

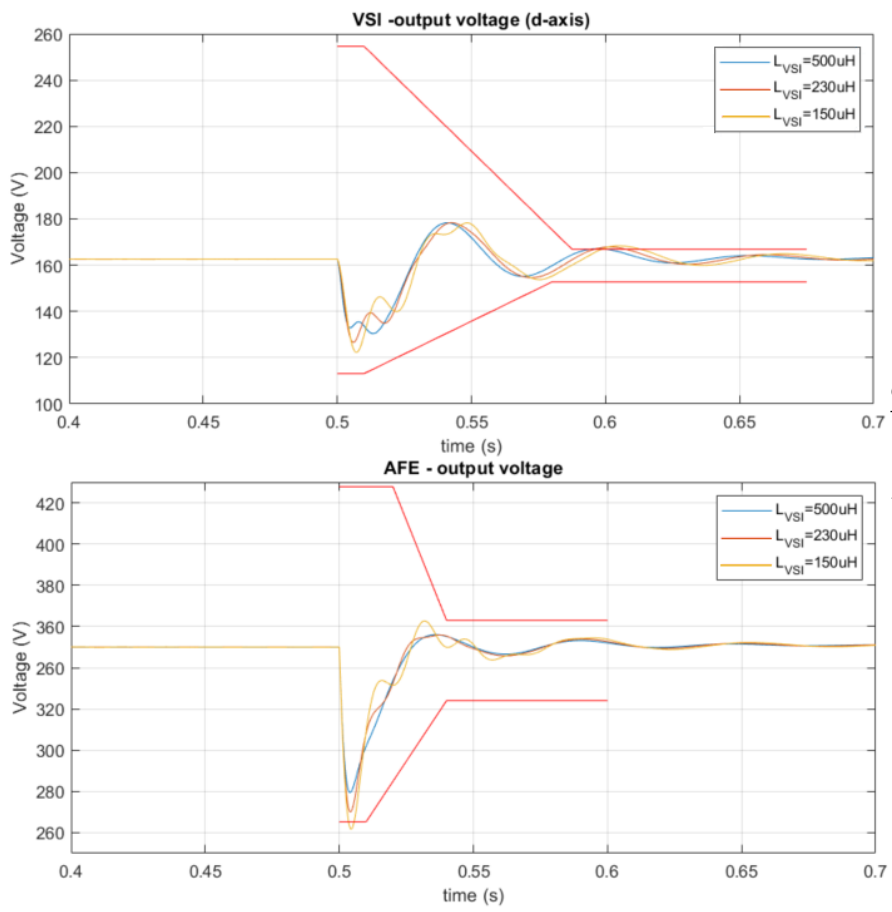

Fig. 6: Comparison of VSI and AFE output voltage response for a nominal power step load (1.5kW) for different VSI output inductor values. All other parameters remain unchanged.

\section{A. Simulation tool description}

The simulation tool is based on the small-signal average model of both VSI and AFE which has been obtained by linearisation of the system in the specified operating point [16]. The system is represented in dq frame as two coupled DC systems for VSI converter and another two for AFE converter. The equations Eq. 6 describe VSI small-signal model including its control (by modulation indexes $m_{d} m_{q}$ ), whereas equations Eq. 7 describe AFE model with its control (modulation indexes $p_{d} p_{q}$ ) VSI and AFE are coupled which can be seen in equations $6 \mathrm{c}, 6 \mathrm{~d}, 7 \mathrm{a}$ and $7 \mathrm{~b}$. The average model representation simplifies the circuit significantly while still being able to simulate dynamics accurately with much less computational and time effort. It is worth noting that the average model ignores all switching effects of the converters, however, it does not affect the system's dynamic behaviour, thus can be neglected [17].

$$
\begin{gathered}
\frac{d I_{d}}{d t}=-\frac{R_{V S I}}{L_{V S I}} I_{d}+\omega I_{q}-\frac{1}{L_{V S I}} V_{c d}+\frac{1}{2 L_{V S I}} V_{d c_{i}} m_{d}(6 \mathrm{a}) \\
\frac{d I_{q}}{d t}=-\frac{R_{V S I}}{L_{V S I}} I_{q}+\omega I_{d}-\frac{1}{L_{V S I}} V_{c q}+\frac{1}{2 L_{V S I}} V_{d c_{i}} m_{q}(6 \mathrm{~b}) \\
\frac{d V_{c d}}{d t}=-\frac{1}{C_{V S I}} I_{d}+\omega V_{c q}-\frac{1}{C_{V S I}} I_{a d} \\
\frac{d V_{c q}}{d t}=-\frac{1}{C_{V S I}} I_{q}+\omega V_{c d}-\frac{1}{C_{V S I}} I_{a q}
\end{gathered}
$$

TABLE II: Simulation tool input parameters.

\begin{tabular}{cc}
\hline VSI & AFE \\
\hline $\mathrm{C}_{D C}=100 \mu \mathrm{F}$ & $\mathrm{C}_{A F E}=100 \mu \mathrm{F}$ \\
$\mathrm{R}_{V S I}=120 \mu \Omega$ & $\mathrm{R}_{A F E}=90 \mu \Omega$ \\
$\zeta=1$ & - \\
$\mathrm{L}_{V S I}=10-2000 \mu \mathrm{H}$ & $\mathrm{L}_{A F E}=10-2000 \mu \mathrm{H}$ \\
$\mathrm{C}_{V S I}=16-160 \mu \mathrm{F}$ & - \\
$\mathrm{f}_{i_{V S I}}=100-1000 \mathrm{~Hz}$ & $\mathrm{f}_{i_{A F E}}=100-1000 \mathrm{~Hz}$ \\
$\mathrm{f}_{v_{V S I}}=10-100 \mathrm{~Hz}$ & $\mathrm{f}_{v_{A F E}}=10-100 \mathrm{~Hz}$ \\
\hline
\end{tabular}

$\frac{d I_{a d}}{d t}=-\frac{R_{A F E}}{L_{A F E}} I_{a d}+\frac{1}{L_{A F E}} V_{c d}+\omega I_{a q}-\frac{1}{2 L_{A F E}} V_{d c_{a}} p_{d}(7 \mathrm{a})$ $\frac{d I_{a q}}{d t}=-\frac{R_{A F E}}{L_{A F E}} I_{a q}+\frac{1}{L_{A F E}} V_{c q}-\omega I_{a d}-\frac{1}{2 L_{A F E}} V_{d c_{a}} p_{q}(7 \mathrm{~b})$ $\frac{d V_{d c_{a}}}{d t}=-\frac{3}{4 C_{A F E}} I_{a d}+\frac{3}{4 C_{A F E}} I_{a q} p_{q}-\frac{1}{C_{A F E} R_{L}} V_{d c_{a}}$

$V_{c d}, V_{c q}, I_{d}$ and $I_{q}$ are VSI output voltage current in dq-frames respectively, $m_{d}$ and $m_{q}$ are VSI modulation indexes in dqframes, $V_{d c_{i}}$ is VSI input voltage. $I_{a d}$ and $I_{a q}$ are AFE input current in dq-frames, $p_{d}$ and $p_{q}$ are AFE modulation indexes in dq-frames, $V_{d c_{a}}$ is AFE output dc-link voltage. $\omega$ is the AC grid angular frequency and $R_{L}$ is the resistance connected to the AFE output and used as grid load for step-response analysis. The other parameters of the model were described in the section III-B.

The simulation tool was created in Matlab environment. It is a script which creates possible combinations of the system variables which play significant role in the dynamic behaviour - VSI LC filter, AFE input filter, both VSI and AFE controllers bandwidths. Any other values of the system (such as both converters DC capacitors, inductors parasitic resistance and damping factor) were constant in the analysis. The variables range was set according to the controller estimated limits (for instance, there was no stable controller with a $C_{V S I}$ capacitance smaller than $16 \mu \mathrm{F}$ ) and technological limits (sampling frequency of the measurement system). The table with both variables and fixed values is presented in Table II. The variables are defined as input vectors in the script. Then the script runs the simulation numerous times in order to examine all possible combinations for each variable value. During each simulation the system resistive step-load response is checked. The script checks the system stability and whether the requirements are met.

\section{B. Area of Design}

Once the results were obtained it was necessary to process the data. For each set of physical variables (LC and L filters components values) it was tested if there exists at least one set of non-physical variables (controllers bandwidths) where the system is able to meet the standards. In other words, if it is possible to design a controller which is able to meet the standards for a particular set of passive components values. The boundaries of the design parameters are given in Table II. It is important to notice that the controller maximum bandwidth have been set to $1 \mathrm{kHz}$ due to hardware limitations (analog to digital converter sampling frequency) as explained in Section V. This is to underline the multi-constrained design problem. All data was composed together and presented as the 


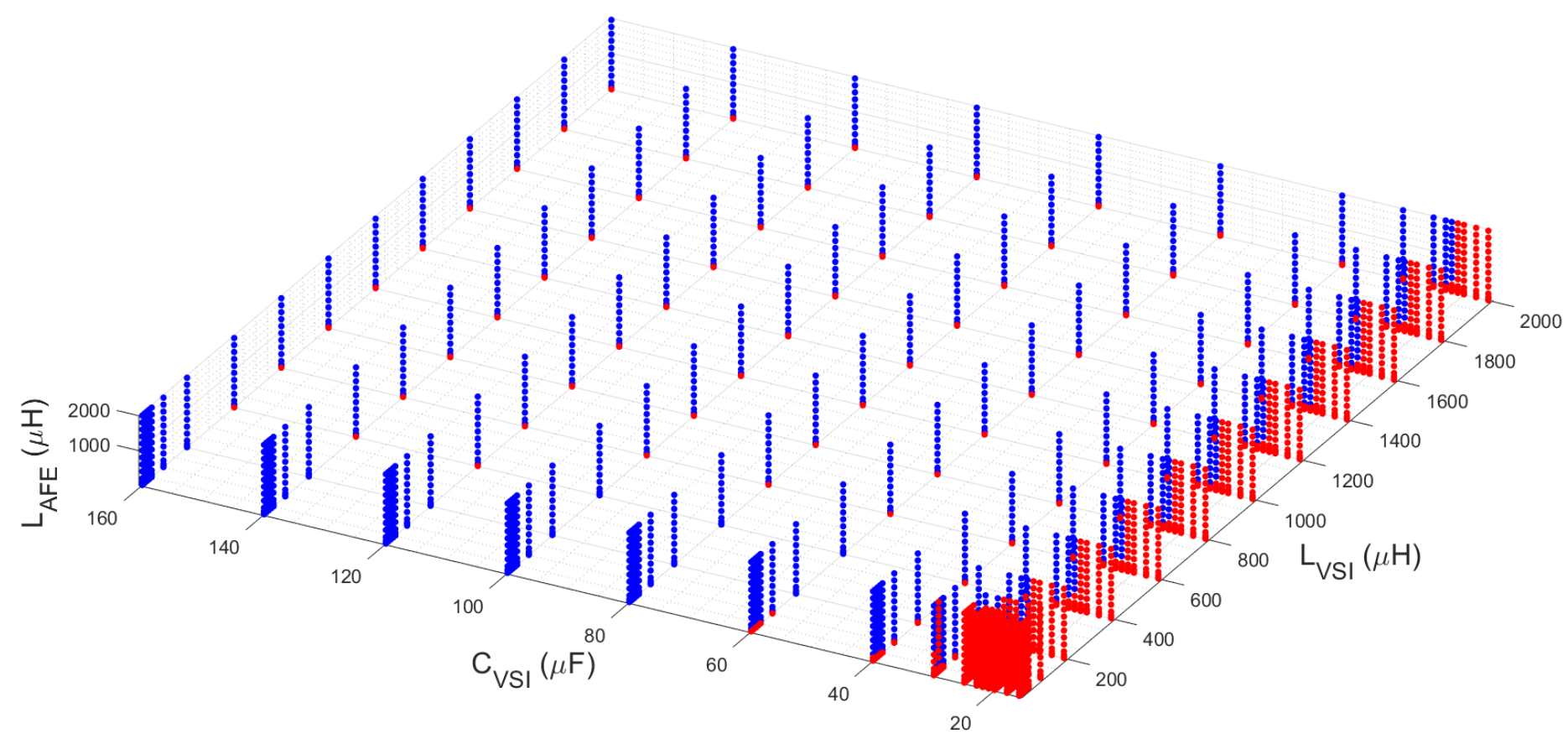

Fig. 7: Area of Design. Blue points indicates the design which meets the requirements, red which does not.

Area of Design (AoD) (Fig.7). Blue dots showing the design where meeting the requirements is possible and the red ones where it is not. This figure was obtained for a load step equal to the nominal power of the system, what is considered as the worst case. It needs to be mentioned that the Area of Design considers only control aspect, there might be a lot of designs which do not comply with power quality standard for a given switching frequency. This aspect will be studied in the last section of this paper.

The AoD shows that control aspect needs to be considered when designing the filters so that there is a link between power quality and control aspects. For some sets of the grid filters, even if they meet the power quality standards, it might be not possible to design a control system which meets the dynamic standards. Therefore, some design constraints have to be defined especially when there is a need of minimizing the filters (e.g. through optimization) for saving converter's weight or cost, for instance. In order to be easily used in a design process, the scattered data of Fig.7 have been interpolated and transfered into three individual constraints for each components in Fig. 8-10. The constraints represented by surfaces are defined as follows: $L_{V S I} \geq f\left(C_{V S I}, L_{A F E}\right)$, $C_{V S I} \geq f\left(L_{V S I}, L_{A F E}\right), L_{A F E} \geq f\left(L_{V S I}, C_{V S I}\right)$. It can be seen from these individual constraints that there is a minimum value for each component depending on the others. For high values of filter parameters, there might be no more constraint. For instance, it can be deduced from Fig. 10 that if $\mathrm{C}_{V S I}>$ $60 \mu \mathrm{F}$, there is no more constraint on $\mathrm{L}_{A F E}$. In Fig. 8, the minimal value of $\mathrm{C}_{V S I}$ to have no more constraint on $\mathrm{L}_{V S I}$ is $80 \mu \mathrm{F}$. Therefore, having $\mathrm{C}_{V S I}>80 \mu \mathrm{F}$ allows choosing any value for $\mathrm{L}_{A F E}$ and $\mathrm{L}_{V S I}$ : the two systems are fully decoupled.

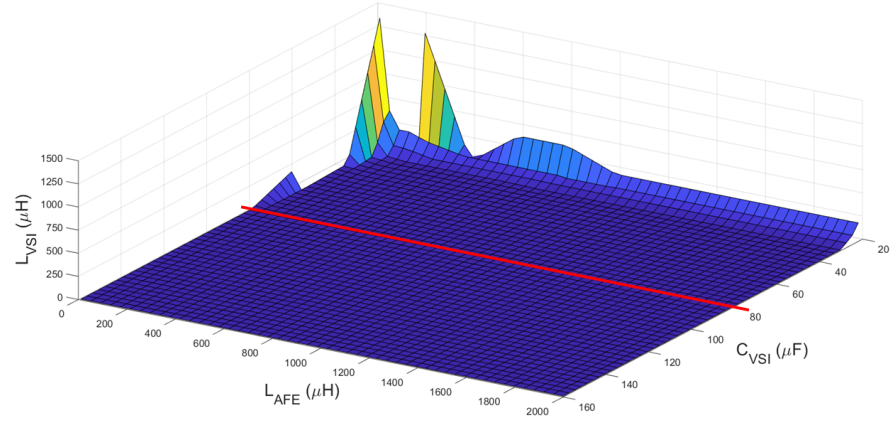

Fig. 8: $\mathrm{L}_{V S I}$ design constraints.

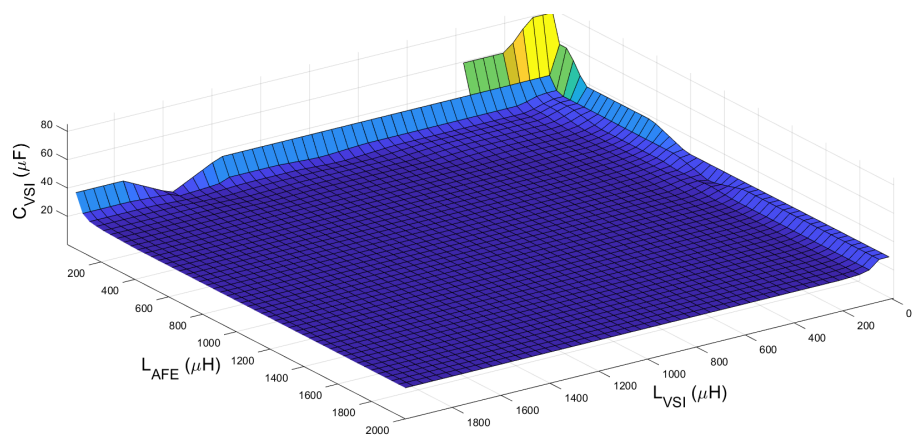

Fig. 9: $\mathrm{C}_{V S I}$ design constraints.

\section{EXPERIMENTAL VERIFICATION}

\section{A. Experiment setup}

In order to validate the control system simulation tool and hence the analysis results, a prototype rig has been built. The 


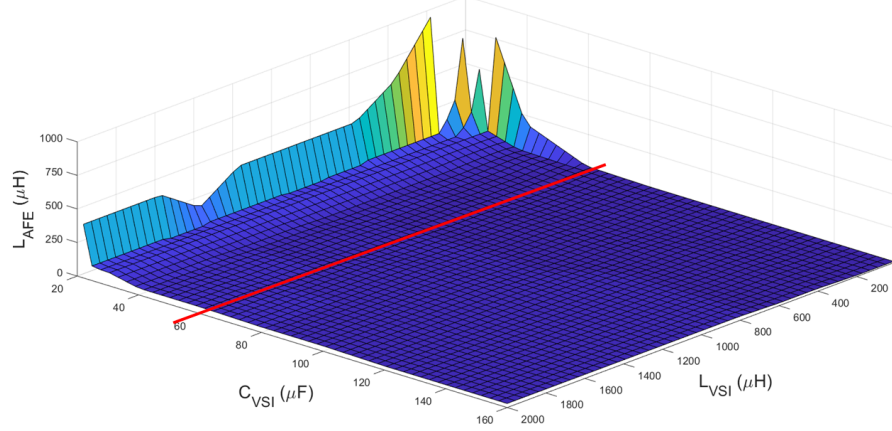

Fig. 10: $\mathrm{L}_{A F E}$ design constraints.

prototype has downscaled parameters since it was not feasible to built MW set-up in the laboratory. The rig elements are following: DC power supply, VSI and AFE converters, grid harmonic filters, controller PCB board and resistive load. The experimental setup is presented in Fig. 11. The converter's control is realized by software installed in FPGA-DSP board. The rig's parameters used in experiments are shown in Table III. The values are slightly different to the designed ones due to manufacturing limits. The waveforms were recorded through oscilloscope and ADC channels of the controller. The view of the oscilloscope measurement is presented in Fig. 12. The grid's voltage oscilloscope measurement for parameters from a Table III showed that the the THD standard is definitely met $(\mathrm{THD}=0.38 \%)$ which shows that the filters are oversized.

TABLE III: Experimental setup nominal parameters

\begin{tabular}{cc}
\hline VSI & AFE \\
\hline $\mathrm{P}_{N}=1.5 \mathrm{~kW}$ & $\mathrm{P}_{N}=1.5 \mathrm{~kW}$ \\
$\mathrm{~V}_{\text {in }}=350 \mathrm{~V} \mathrm{dc}$ & $\mathrm{V}_{\text {in }}=115 \mathrm{~V} \mathrm{AC} \mathrm{\textrm {ms }}$ \\
$\mathrm{V}_{\text {out }}=115[\mathrm{~V}] \mathrm{AC} \mathrm{rms}$ & $\mathrm{V}_{\text {out }}=350 \mathrm{~V} \mathrm{dc}$ \\
$\mathrm{f}_{s w}=20 \mathrm{kHz}$ & $\mathrm{f}_{\text {sw }}=20 \mathrm{kHz}$ \\
$\mathrm{f}_{n}=400 \mathrm{~Hz}$ & - \\
$\mathrm{L}_{V S I}=260 \mu \mathrm{H}$ & $\mathrm{L}_{A F E}=630 \mu \mathrm{H}$ \\
$\mathrm{R}_{V S I}=120 \mu \Omega$ & $\mathrm{R}_{A F E}=90 \mu \Omega$ \\
$\mathrm{C}_{V S I}=33 \mu \mathrm{F}$ & $\mathrm{C}_{A F E}=100 \mu \mathrm{F}$ \\
\hline
\end{tabular}

\section{B. Tests results}

During the experiments the resistive load was connected to the AFE output in order to test the system step-load response. The process was conducted for several different harmonic filters components and controllers bandwidths setups. Then the results were compared with the simulations for corresponding parameters. The passive components used in the experiments are $\mathrm{C}_{V S I}=33 \mu \mathrm{F}, \mathrm{C}_{V S I}=25 \mu \mathrm{F}, \mathrm{L}_{A F E}=630 \mu \mathrm{H}, \mathrm{L}_{A F E}=345 \mu \mathrm{H}$ and $\mathrm{L}_{V S I}=260 \mu \mathrm{H}$.

In order to compare the simulation with the measurement the VSI output voltage had to be presented in dq-frame, therefore, the measurement used for comparison was based on the controller ADC channels. The ADC channels measure all three phases so they provide sufficient amount of data to perform abc-dq transformation.

The test results proved the validity of the control system simulation tool. The average model used in the tool is accurate

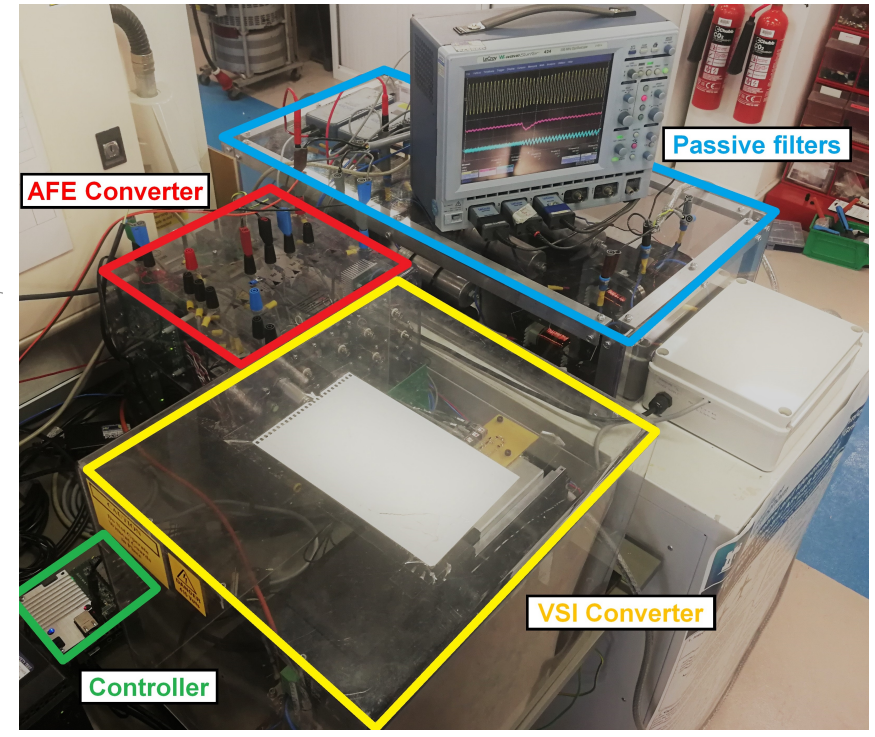

Fig. 11: Experimental test rig.

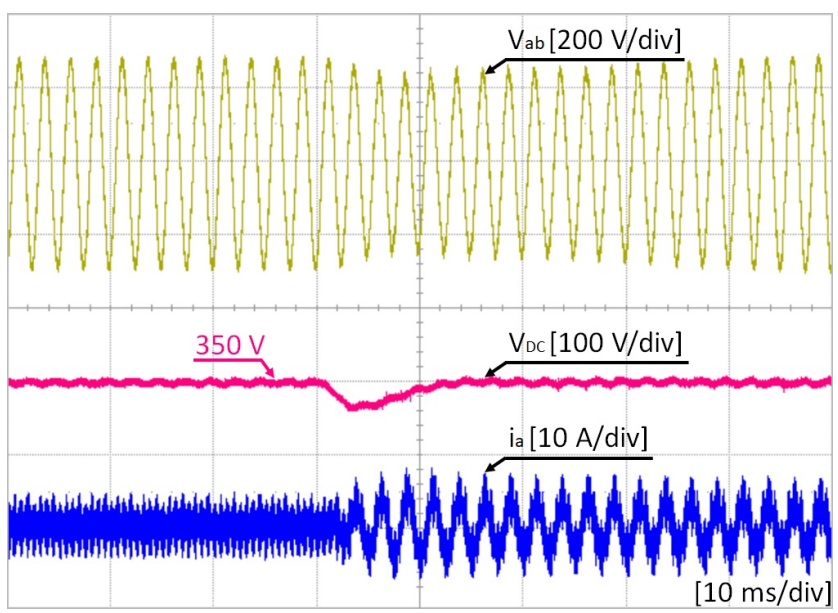

Fig. 12: Converters waveforms acquired by oscilloscope. Yellow - VSI output voltage Pink - AFE output voltage Blue AFE input current.

enough in comparison with the measurements. Even if the waveforms do not fit perfectly, the dynamic behaviour is well reproduced, in every case that had been studied. Regardless of the requirements compliance, the results of the simulation and the experiment were the same. Selected results for different filter components and controller parameters are presented below. Fig. 13 and Fig. 14 present the cases where the standards were met whereas Fig. 15 and Fig. 16 present the cases where requirements were not met. 

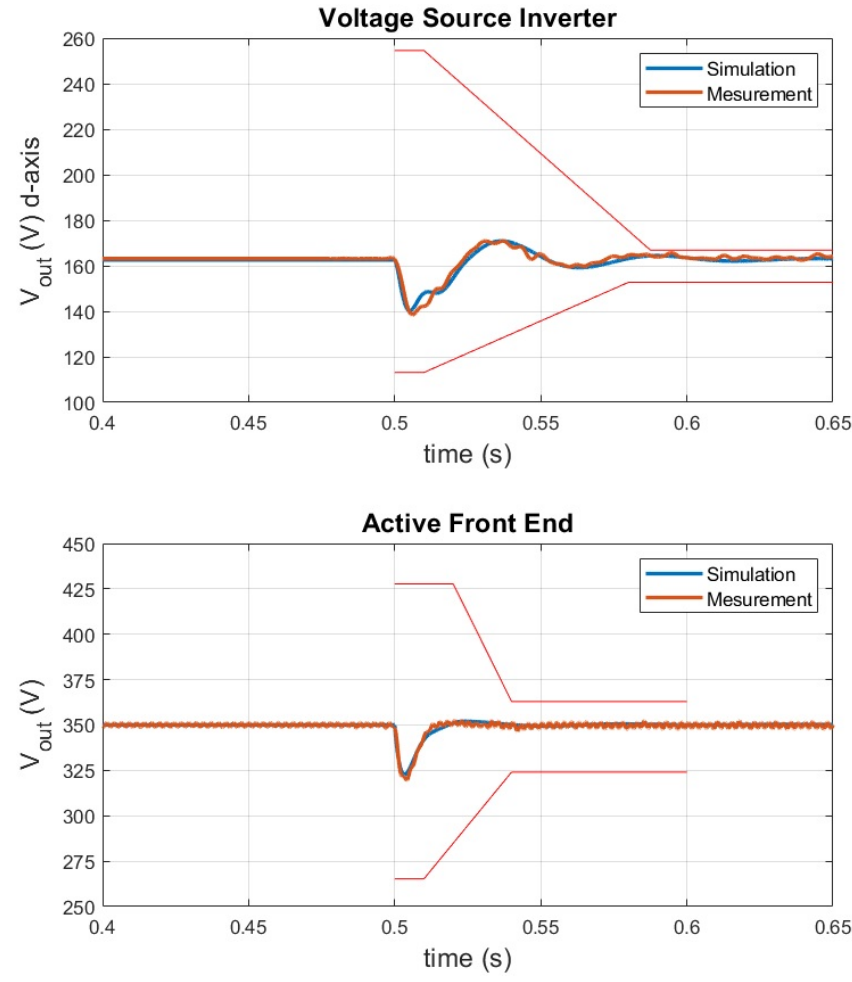

Fig. 13: Comparison between simulation and experimental results of step-load response of the system. The passive components parameters are $L_{V S I}=260 \mu \mathrm{H} C_{V S I}=33 \mu \mathrm{F}$
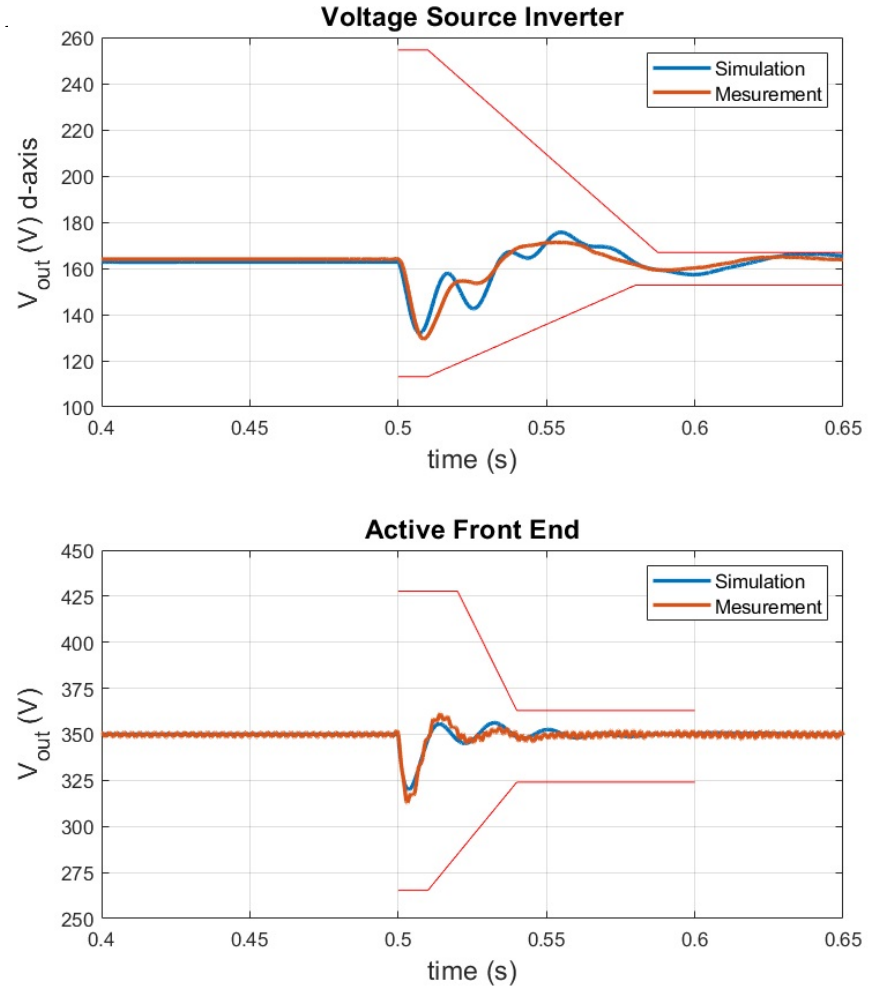

Fig. 14: Comparison between simulation and experimental results of step-load response of the system. The passive components parameters are $L_{V S I}=260 \mu \mathrm{H} C_{V S I}=33 \mu \mathrm{F}$ $L_{A F E}=345 \mu \mathrm{H}$.
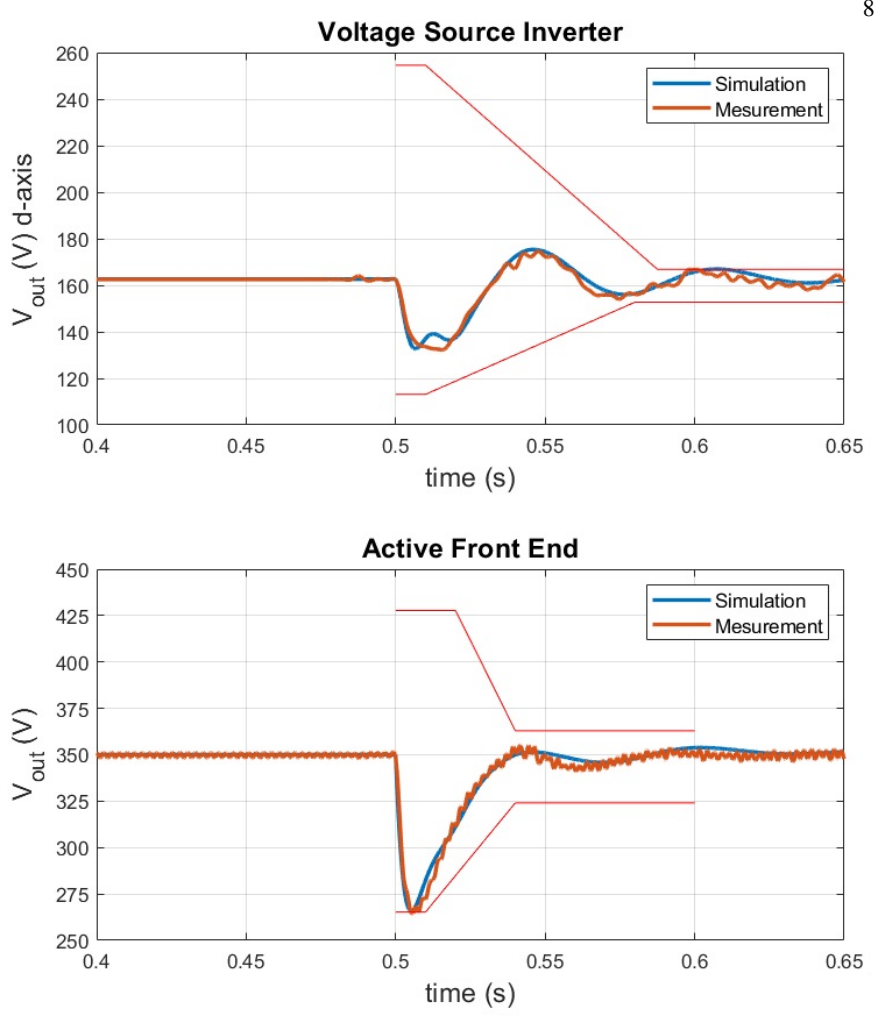

Fig. 15: Comparison between simulation and experimental results of step-load response of the system. The passive components parameters are $L_{V S I}=260 \mu \mathrm{H} C_{V S I}=33 \mu \mathrm{F}$ $L_{A F E}=345 \mu \mathrm{H}$.
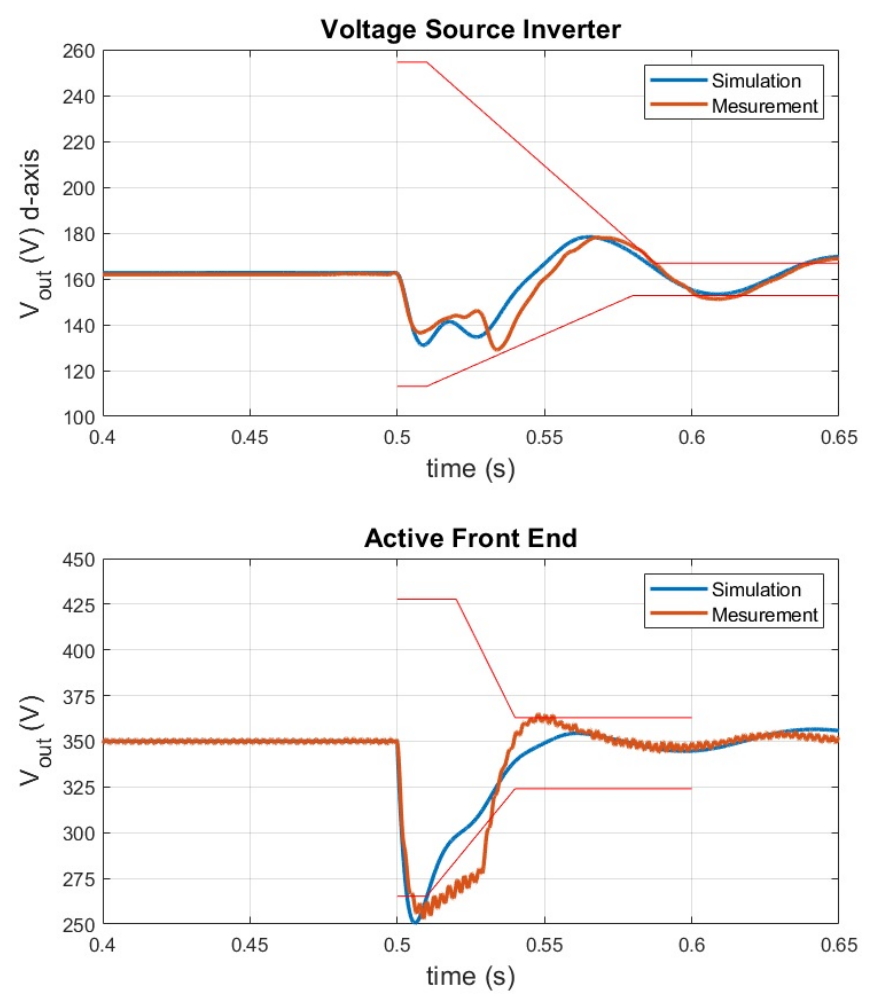

Fig. 16: Comparison between simulation and experimental results of step-load response of the system. The passive components parameters are $L_{V S I}=260 \mu \mathrm{H} C_{V S I}=25 \mu \mathrm{F}$ $L_{A F E}=345 \mu \mathrm{H}$. 


\section{FILTERS OPTIMIZATION}

In order to highlight the importance of the influence of the filters interactions on both power quality and dynamic behaviour the grid filters weight simple optimization has been conducted. In the optimization process, the variables are the values of the filter elements $\left(\mathrm{L}_{A F E}, \mathrm{~L}_{V S I}, \mathrm{C}_{V S I}\right)$. The objective function is the total mass of the filter. It is obtained by adding the contribution of each component. The mass of $\mathrm{C}_{V S I}$ is simply interpolated from the manufacturer catalogue, for rated voltage and current. For inductors, there are no standard devices, therefore a full design process has been implemented, already described in [18]: during this step, the core size, turn number are chosen according to the desired inductance. Technological constraints of the model are maximum flux density to avoid saturation, maximum current density in the windings, maximum turn number in the winding window and maximum core losses.

The optimization problem is therefore presented as follows:

$$
\text { Mass }_{\text {filters }}=\operatorname{minf}\left(L_{V S I}, C_{V S I}, L_{A F E}\right)
$$

with following constraints:

- Minimum and maximum values for input parameters $\left(16 \mu \mathrm{F}<\mathrm{C}_{V S I}<160 \mu \mathrm{F}, 0.01 \mathrm{mH}<\mathrm{L}_{A F E}, \mathrm{~L}_{V S I}<2 \mathrm{mH}\right)$

- Power quality: Voltage THD $<5 \%$.

The optimization has been carried out with the use of gradientbased Sequential quadratic programming (SQP) algorithm [19].

The first optimization was carried out using these constraints only, and then the second one adding the dynamic constraints expressed by the design rules obtained in subsection IV-B and illustrated in Fig.8-10.

\section{A. Grid frequency-domain model}

In order to be able to perform quick computations of the grid's THD for different sets of the filter values, a frequency- domain grid model was created (Fig. 18). The model is simplified to one-phase frame assuming the phase balance. Voltage sources $\mathrm{V}_{V S I}$ and $\mathrm{V}_{A F E}$ are frequency-domain phase-ground voltages of VSI and AFE respectively. This model was included in the optimization algorithm and used to compute $\mathrm{AC}$ grid voltage THD.

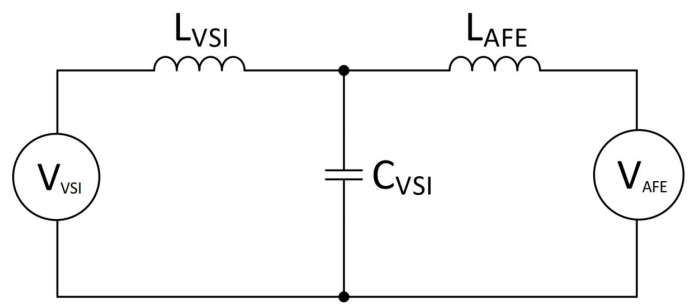

Fig. 18: Frequency-domain model of the grid.

\section{B. Optimization with power quality constraints}

The first optimization was carried out only with power quality constraints taken from MIL704F avionic standard. Specifically, with maximum grid $\mathrm{THD}=5 \%$. The nominal filters weight (before optimization) was estimated to Mass $_{\text {filters }}=1866.5 \mathrm{~g}$. Afterwards the optimization filters' weight was estimated to Mass $_{\text {filters }}=500.37 \mathrm{~g}$. The optimized filters values are $\mathrm{L}_{V S I}=51.4 \mu \mathrm{H}, \mathrm{C}_{V S I}=23 \mu \mathrm{F}$ and $\mathrm{L}_{A F E}=24.9 \mu \mathrm{H}$. The big difference between non-optimized and optimized filters stems from the fact that previously designed filters were oversized due to a simple design approach instead of extensive harmonic analysis. Inductances are much smaller than in the initial design which results in higher current ripples. However, a time domain simulation shows that the system works properly. The voltage THD constraint, which is the only limitation in the standard, is met despite this high current ripple.

However, the stability analysis shows that the optimization results, even if they respect the power quality standards

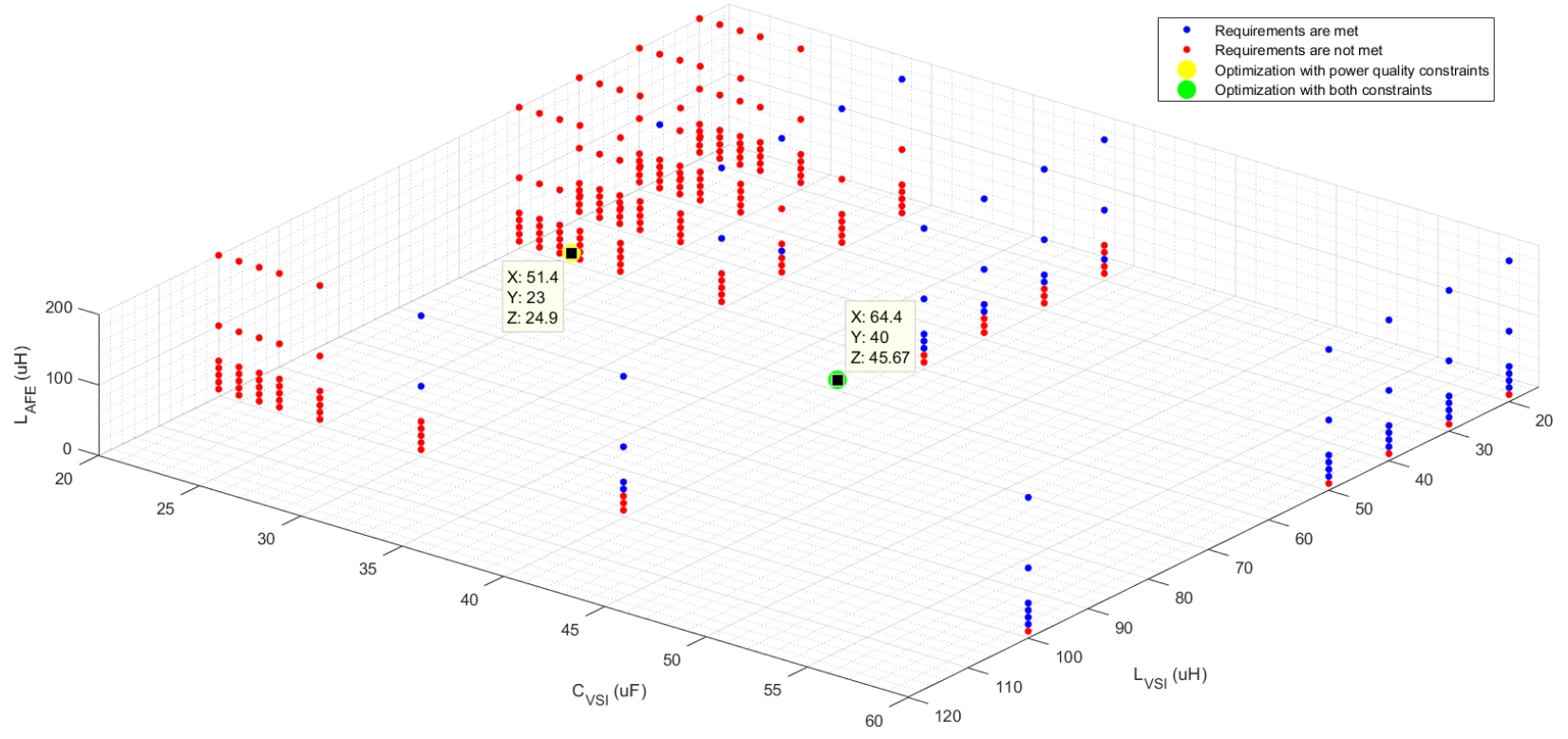

Fig. 17: Zoomed part of the Area of Design with optimized solutions. 
(THD $=4.99 \%$ ), do not allow to design a stable controller for the considered system.

\section{Optimization with power quality and dynamic constraints}

Due to the fact that the previous optimization result was not sufficient in terms of control, the second optimization has been carried out including both power quality and dynamic requirements. The dynamic requirements constraints included in the optimization algorithm are shown in Figs. 8-10. The optimization result is different to the one given by the case with only power quality constraints. The estimated filters weight is Mass $_{\text {filter }}=652.20 \mathrm{~g}$. The optimized filters values are $\mathrm{L}_{V S I}=64.4 \mu \mathrm{H}, \mathrm{C}_{V S I}=40 \mu \mathrm{F}$ and $\mathrm{L}_{A F E}=45.67 \mu \mathrm{H}$. The grid's voltage $\mathrm{THD}=2.09 \%$. The average model simulation results with optimized filters parameters are presented below in the Fig. 19 and switching model simulation results are presented in the Fig. 20. The Fig. 17 shows the obtained results from both optimizations in the AoD part. It is clear in this figure that the dynamic constraints have moved the filter values to another location of the AoD, resulting in slightly increased mass but also better THD which is no more the active constraint in the optimization.
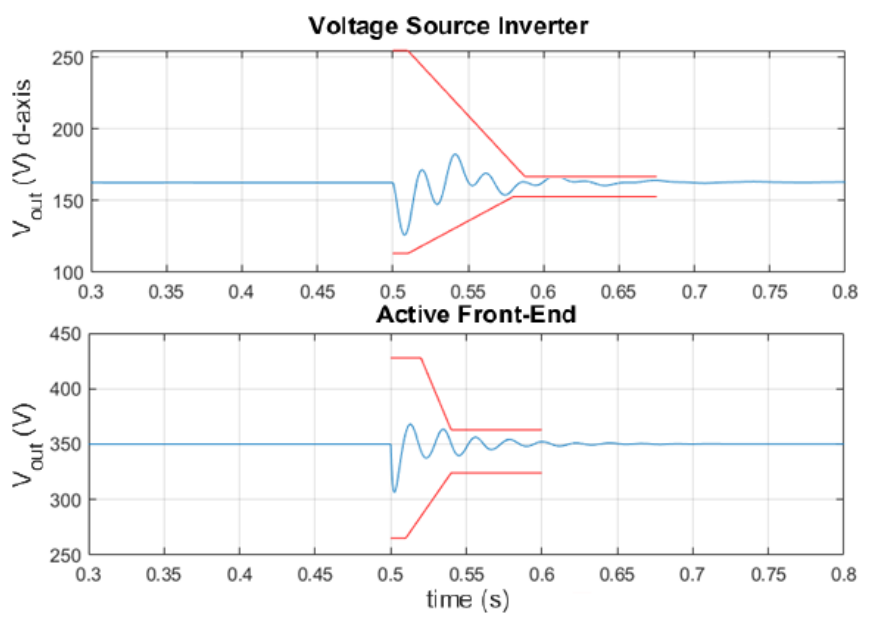

Fig. 19: Avarage model simulation result with optimized filters.

\section{CONCLUSION}

The analysis carried out and presented in this paper revealed the interactions between harmonic filters of the converters connected to the aircraft grid. The interactions have a significant impact on the control performance. Therefore, for some of the filters designs, even if they meet the harmonic requirements, it could be impossible to design a controller which would be able to comply with the control standards. The optimization highlighted the importance of the influence of the interactions. If the interactions are not considered in the optimization, the system with the optimized filters might not work correctly due to control issues. This paper has illustrated how to implement the dynamic constraints in the optimization process. It focused on the AC filter design, without changing the converters parameters. Combining this approach with other
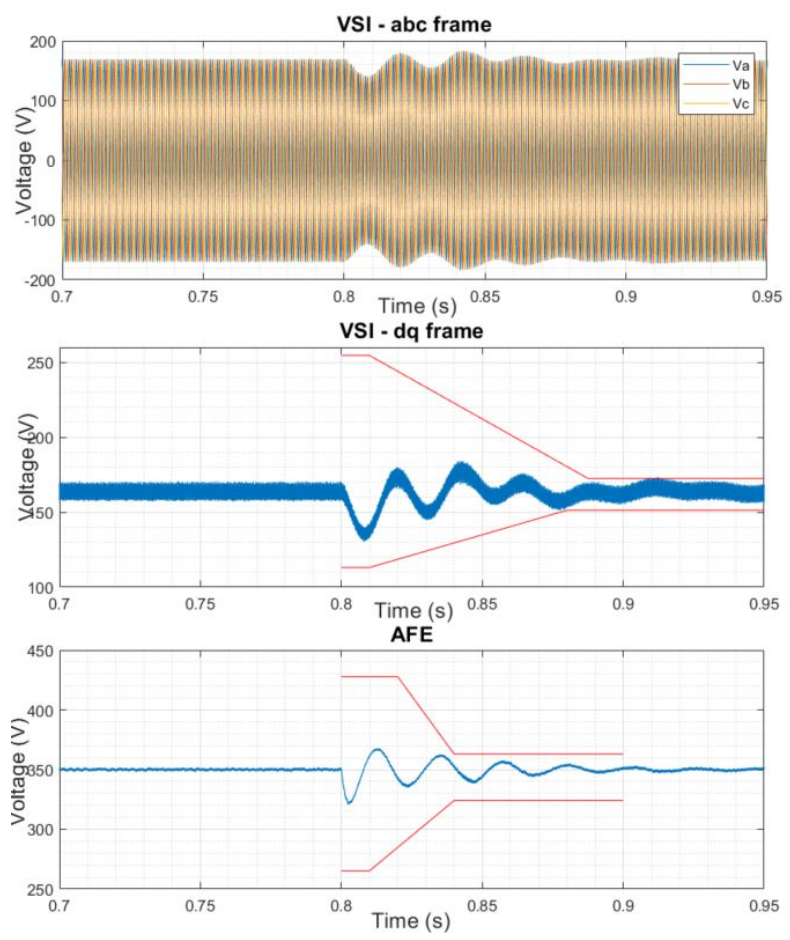

Fig. 20: Switching model simulation result with optimized filters.

work such as [18] might help the designer fully address all of the constraints in a system optimization. In particular, switching frequency and DC filters might be included in the process.

\section{REFERENCES}

[1] B. Rahrovi and M. Ehsani, "A review of the more electric aircraft power electronics," pp. 1-6, 2019.

[2] K. Emadi and M. Ehsani, "Aircraft power systems: technology, state of the art, and future trends," IEEE Aerospace and Electronic Systems Magazine, vol. 15, no. 1, pp. 28-32, 2000.

[3] B. Sarlioglu and C. T. Morris, "More electric aircraft: Review, challenges, and opportunities for commercial transport aircraft," IEEE transactions on Transportation Electrification, vol. 1, no. 1, pp. 54-64, 2015.

[4] G. Buticchi, S. Bozhko, M. Liserre, P. Wheeler, and K. Al-Haddad, "On-board microgrids for the more electric aircraft-technology review," IEEE Transactions on Industrial Electronics, vol. 66, no. 7, pp. 55885599, 2018.

[5] B. Czerniewski, A. Formentini, D. Dewar, P. Zanchetta, and J. Schanen, "Impact of converters interactions on control design in a power electronics dense network: Application to more electric aircraft," in 2019 21st European Conference on Power Electronics and Applications (EPE '19 ECCE Europe), pp. P.1-P.7, 2019.

[6] E. Fuchs and M. A. Masoum, Power quality in power systems and electrical machines. Academic press, 2011.

[7] M. McGranaghan and D. Mueller, "Designing harmonic filters for adjustable-speed drives to comply with ieee-519 harmonic limits," IEEE Transactions on Industry Applications, vol. 35, no. 2, pp. 312-318, 1999.

[8] T. C. Wang, Z. Ye, G. Sinha, and X. Yuan, "Output filter design for a grid-interconnected three-phase inverter," vol. 2, pp. 779-784, 2003.

[9] H. Kim and S. Sul, "Analysis on output lc filters for pwm inverters," in 2009 IEEE 6th International Power Electronics and Motion Control Conference, pp. 384-389, 2009.

[10] G. L. Calzo, A. Lidozzi, L. Solero, and F. Crescimbini, "Lc filter design for on-grid and off-grid distributed generating units," IEEE transactions on industry applications, vol. 51, no. 2, pp. 1639-1650, 2014.

[11] J. Kim, J. Choi, and H. Hong, "Output lc filter design of voltage source inverter considering the performance of controller," vol. 3, pp. 16591664 vol.3, Dec 2000. 
[12] K. H. Ahmed, S. J. Finney, and B. W. Williams, "Passive filter design for three-phase inverter interfacing in distributed generation," in 2007 Compatibility in Power Electronics, pp. 1-9, IEEE, 2007.

[13] F. Liccardo, P. Marino, C. Schiano, and N. Visciano, "Active front-end design criteria," in 10th International Conference on Harmonics and Quality of Power. Proceedings (Cat. No.02EX630), vol. 2, pp. 507-512 vol.2, 2002

[14] K. Jalili and S. Bernet, "Design of $l c l$ filters of active-front-end two-level voltage-source converters," IEEE Transactions on Industrial Electronics, vol. 56, no. 5, pp. 1674-1689, 2009.

[15] B. Wen, D. Boroyevich, R. Burgos, P. Mattavelli, and Z. Shen, "Analysis of dq small-signal impedance of grid-tied inverters," IEEE Transactions on Power Electronics, vol. 31, no. 1, pp. 675-687, 2015.

[16] S. Hiti, D. Boroyevich, and C. Cuadros, "Small-signal modeling and control of three-phase pwm converters," in Proceedings of 1994 IEEE Industry Applications Society Annual Meeting, vol. 2, pp. 1143-1150, IEEE, 1994.

[17] B. Wen, Stability analysis of three-phase ac power systems based on measured dq frame impedances. $\mathrm{PhD}$ thesis, Virginia Tech, 2015.

[18] A. Voldoire, J.-L. Schanen, J.-P. Ferrieux, B. Sarrazin, and C. Gautier, "Pre-design methodology of voltage inverters using a gradient-based optimization algorithm," IEEE Journal of Emerging and Selected Topics in Power Electronics, 2021.

[19] P. T. Boggs and J. W. Tolle, "Sequential quadratic programming," Acta numerica, vol. 4, pp. 1-51, 1995 . 